\title{
Planning Emergency Shelters for Urban Disasters: A Multi-Level Location-Allocation Modeling Approach
}

\author{
Yijun Shi ${ }^{1}$ **1D, Guofang Zhai ${ }^{2}$, Lihua Xu ${ }^{1}$, Quan Zhu ${ }^{1}$ and Jinyang Deng ${ }^{3}$ \\ School of Landscape Architecture, Zhejiang A\&F University, Hangzhou 311300, China \\ School of Architecture and Urban Planning, Nanjing University, Nanjing 210093, China \\ 3 School of Natural Resources, West Virginia University, Morgantown, WV 26506, USA \\ * Correspondence: yijun_shi@zafu.edu.cn
}

Received: 12 June 2019; Accepted: 7 August 2019; Published: 8 August 2019

check for updates

\begin{abstract}
In recent years, cities are threatened by various natural hazards. Planning emergency shelters in advance is an effective approach to reducing the damage caused by disasters and ensuring the safety of residents. Thus, providing the optimal layout of urban emergency shelters is an important stage of disaster management and an act of humanitarian logistics. In order to study the optimal layout of emergency shelters in small mountain cities, this paper constructs multi-level location models for different grades of emergency shelters so as to minimize the travel and construction costs and maximize the coverage rate. Specifically, the actual service of emergency shelters is determined using Geographic Information System (GIS) software and Weighted Voronoi Diagram (WVD) models under the limitation of site capacity, and the space layout is adjusted through combining the actual urban land with the construction position. In this paper, the Jianchuan county seat at Yunnan Province, China, was considered as a case study to illustrate the models of emergency shelters in which the feasibility of the presented models is verified. The proposed research methods and models have provided theoretical basis and a benchmark for the optimal layout of emergency shelters in other small mountain cities.
\end{abstract}

Keywords: Emergency shelters; multi-level location models; services scope; small mountain city

\section{Introduction}

In recent years, with increased urbanization in China, different cities have been facing increased hazards of various types [1], which can be both natural (e.g., earthquakes, tsunami, typhoon, hurricanes, etc.) and man-made (e.g., chemical leakages, terrorist attacks, etc.). Frequent urban disasters have caused huge casualties and property loss in cities and highlighted the lack of efficient strategies for disaster prevention and hazard mitigation [2,3]. Simultaneously, when a disaster occurs, if individuals do not have a number of security emergency shelters, together with the general public's lack of basic knowledge of the disaster prevention safety, it is likely to lead to chaos in the social order and among the public, cause serious social unrests and losses, and endanger the public safety of cities [4]. Emergency shelter is one of the most important tools now in disaster relief operations and it is also a concrete manifestation of humanitarian logistics, which can be used both for an immediate response and for long-term measures [5]. Planning emergency shelters in advance is an effective approach to reducing the damage caused by disasters and ensuring the safety of residents. It is an important stage of disaster management [6], and the scientific soundness of an emergency shelter's location directly affects the success or failure of rescue work. In order to solve the optimal or approximate solution of other variables (e.g., transportation cost, demand, time, etc.) the basic approach is to select alternate sites 
first, and then utilize the conditional constraints (e.g., site area limitation, maximum facility coverage, etc.) [7].

Much research has addressed this problem through building location models. The primary location models include $p$-center model, $p$-median model, location set covering model, and maximal covering location model. Hakimi first proposed the $p$-median model and the $p$-center model to minimize travel costs [8]. The $p$-median model is mainly used to reduce the total cost of facility configuration and the $p$-center model is mainly used for minimizing the maximum distance from any demand point to the facility. Roth and Toregas first proposed the location set covering model to analyze the location problem of emergency service facilities $[9,10]$, i.e., fire stations and ambulances, to ensure that all the demanding points were covered and at the same time with the smallest total number of facilities or the lowest total construction cost of the facility. Church and ReVelle put forward the maximum coverage model to determine the number of facility points with their number of facilities and coverage radius to ensure the optimal number of coverage points and maximum coverage area of each [11].

Based on these four primary models, various location models were developed, which were extended by assigning different constraint conditions and parameters. Sweeney and Tatham divided the dynamic time into a number of specific periods, based on which, a dynamic model with profit maximization as the goal was established to solve the multi-stage dynamic location problem of a single warehouse [12]. Alcada-Almeida et al. introduced a multi-objective location model to determine the number and location of emergency shelters and the evacuation routes that evacuees should follow [13]. Huang et al. addressed a variation of the $p$-center model with the additional assumption that a facility fails to respond to the demands from the same node, which is likely to happen to many local facilities in large-scale disasters [14]. Considering the uncertainty of demand, Murali et al. formulated a special case of the maximal covering location model with a loss function, to account for the distance-sensitive demand, and chance constraints to address the demand uncertainty [15]. In addition, they illustrated the use of the model in LA County. Huang et al. proposed a general fuzzy multi-objective model to solve the maximal coverage problem with distance constraints, and the solution is put forward by using a GIS-supported Ant algorithm [16]. Zhao et al. formulated an integrated location-allocation model based on time-varying demand analysis for emergency management and applied the model in the emergency shelters planning of Shanghai [3]. Ng et al. proposed a hybrid bi-level model that balances both behavioral assumptions to minimize the total evacuation time and the individual evacuation time [17]. Chang and Liao proposed the location model, which uses space syntax and road-closure indices to identify where to locate emergency shelters based on behavior analysis [18].

With more parameters considered, all models noted above have become more complicated, making them difficult to follow and apply. Although several scholars have put forward a variety of efficient algorithms, most of them are still limited in terms of theoretical development or the realization of a single case. The $p$-median model, $p$-center model, and coverage model are common location models with widespread applications $[9,19]$. These three models laid the foundation for the construction of the location model in our manuscript. In the selection process of urban emergency facilities, an appropriate model should be chosen according to the characteristics of the facilities. A single model cannot simultaneously meet all the problems encountered in the process of emergency facility location. Thus, given the multi-level nature of different types of emergency shelters, different models are taken into account through building multi-level location models of emergency shelters.

Since none of the mentioned models could take into consideration the capacity limitation and population imbalance distribution of emergency shelters in the process of locating, some research put forward the solution by dividing the reasonable service scope of emergency facilities based on location selected. Meng et al. [20] and Xue [21] considered service scope, accessibility, and travel distance in order to analyze the service scope of emergency shelters according to the location analysis model in economic geography. Kılc1 et al. proposed a model based on mixed integer linear programming to select the location of temporary evacuation sites [22]. This mathematical model considered the capacity 
limitations of emergency shelters while determining the location of emergency shelters. Based on the location-configuration model, Zhou et al. transformed the scope of facilities services into mathematical programming problems to maximize or minimize the optimal or feasible location [23]. This method was essentially the same as the location model that fails to consider the scale of the site. A number of studies have differentiated the service scope based on spatial analysis performed by ArcGIS software [23-25]. However, to the best of our knowledge, these methods are still not able to solve the issue of the scale of the emergency shelters by using the number of people to accommodate as evenly distributed, which is certainly inconsistent with real-world conditions. Therefore, the multi-level location models with the service scope analysis may provide a better approach to simulating the people's location choice behavior in practice as well as simulating the actual service scope of each emergency shelter. In this paper, we consider these factors, thus making an important contribution to the literature.

Our article mainly focuses on small mountain cities and offers two contributions. Firstly, we put forward the multi-level location models for different grades of emergency shelters in order to minimize the travel and construction costs and to maximize the coverage rate. Secondly, the limitation of site capacity is included in the service scope of emergency shelter. In this paper, in order to define the scope of urban emergency shelter services, we developed a method that determines the service scope of each emergency shelter by weighted spatial scope. The proposed research methods and models are applied to Jianchuan, a typical small mountain city in China. This paper has provided theoretical basis and a benchmark for the optimal layout of emergency shelters in other small mountain cities.

Our article takes the spatial layout of emergency shelters in small mountainous cities as the research object. Through the three steps of location, zoning and optimization, the whole process of optimizing layout is realized through: (a) constructing a multi-level location models system suitable for different levels of emergency shelters, applying the models to the actual location selection of the emergency shelter in the Jianchuan county seat, and verifying the scientificity and effectiveness of the construction models; (b) establishing a method suitable for the service scope division of emergency shelters in small mountainous cities, and relying on GIS technology to visualize the results; (c) adjusting the location and quantity of emergency shelters in conjunction with population and urban land use within the scope of emergency shelters.

\section{Description of Studied Region and Materials}

China is a mountainous country with complex geological structures, where a variety of natural disasters occur. Yunnan Province is located in the Yunnan-Guizhou Plateau of Southeastern China, where $94 \%$ of the whole province area is mountains. Among 125 counties and cities located in Yunnan Province, there are only 13 cities with less than 7 degrees of fortification intensity, while there are 56 cities beyond 8 degrees. Most of these cities are located in mountainous areas. Facing the interacted pressures of both urban land restrictions and complex geological structures, layout planning for an emergency shelter system is more prominent. In view of this, this paper used Jianchuan as a case study area to explore the optimal layout of emergency shelters in mountain towns.

Located in the northwest of Yunnan Province, China (see Figure 1), Jianchuan county is situated in the southeast of the Qinghai-Tibet Plateau and in the southern part of the Hengduan Mountains. The regional geology of this county belongs to the middle section of the three-river fold belt, which contains several fault zones. Moreover, its geological structure is complex and magmatic activities are frequent as well, thanks to its geographical proximity to the tectonic belt and its correlation with seismic activities (Figure 1). In 2017, a total of 53,600 people lived in a $3.11-\mathrm{km}^{2}$ built-up area in the county seat, a small town in terms of population and land scale. Regarding its geological characteristics, although the county is located in an area of relatively flat terrain, the possibility of the occurrence of geological disasters still exists in the west and northwest of the town. In addition to the complicated geological characteristics of Jianchuan, all types of disasters have happened frequently, according to incomplete statistics (since $886 \mathrm{AD}$, in Jianchuan, 13 earthquakes occurred with a magnitude of over 5 Richter). 


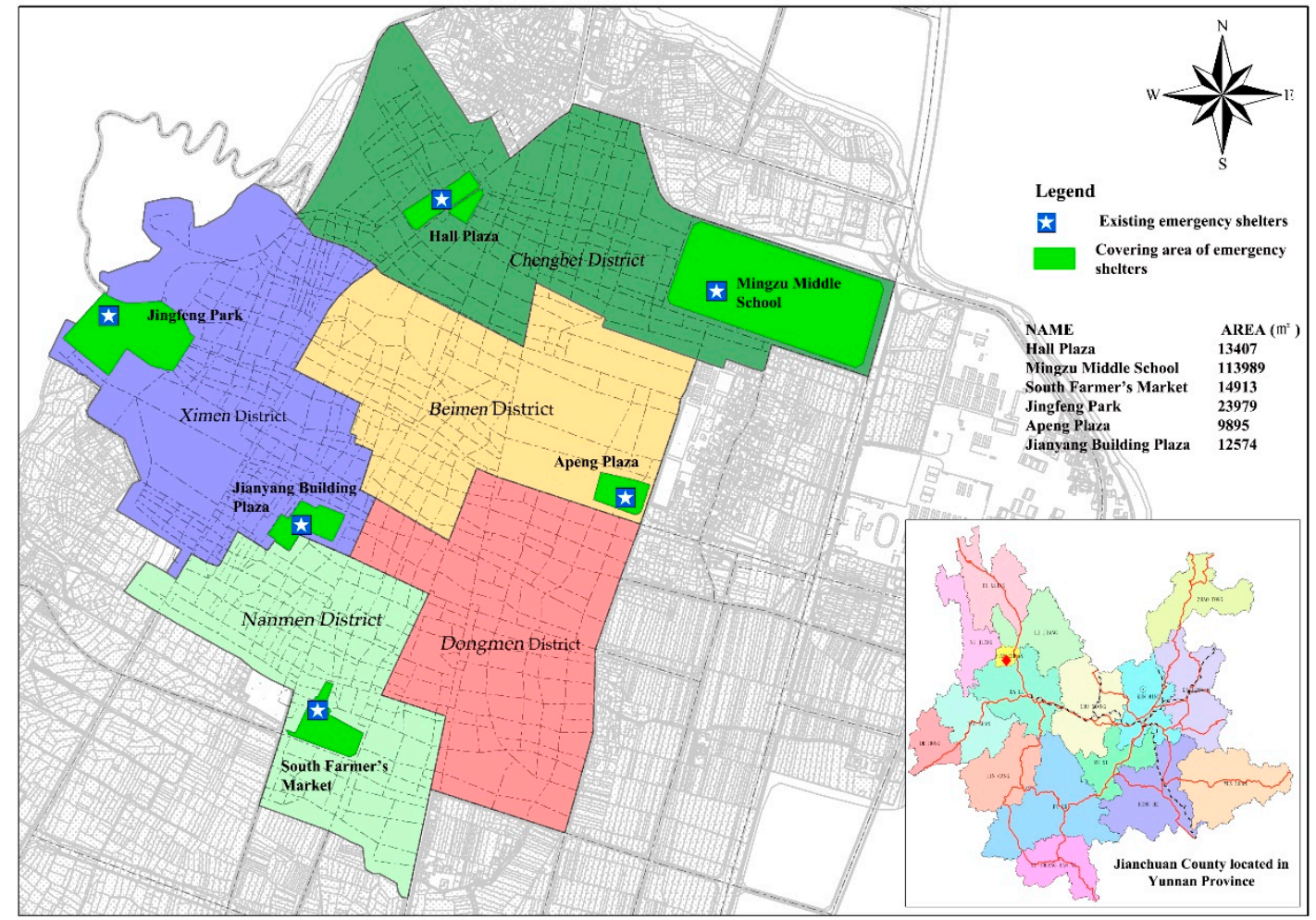

Figure 1. The current condition and location of the Jianchuan county seat.

There were six existing emergency shelters in the Jianchuan county seat as of 2017 (see Figure 1). Although the overall layout of the emergency shelter facilities in the county seat was consistent with its urban layout, challenges still exist. First, the layout of emergency shelters lacked rationality. Due to the insufficiency of urban land, most of the existing urban emergency shelters are indeed the existing parks, squares, schools, public green spaces, and so on. Consequently, it is difficult to ensure the reasonable locations of the emergency shelters. The emergency shelters in the county seat have been mainly located in the north and south of the county seat, and there is no emergency shelter in the center. Second, the scale of emergency facilities was unclear, and the system was mixed. A clear urban emergency shelter system is essential during evacuation conditions and post-disaster relief operations. However, there were no corresponding provisions on the scale of emergency shelters in the master plan of the Jianchuan county seat. Third, the allocation of emergency shelter facilities was not reasonable. Due to the tightness of land use, the existing emergency shelters are mainly configured by using existing parks, plazas, schools, and public green spaces, rather than according to the distribution of the population and the distribution of disasters. From the perspective of the distribution of disasters, the risk of landslides in the northern regions is greater due to the proximity to the mountains. In the ancient city area of the central region, the risk of fire is high because the building materials are mostly wood structures. The disaster risk in the southern region is relatively low. Moreover, the emergency shelters that have been set up are mainly concentrated in the northern and southern parts of the town, but not in the central areas. Meanwhile, the population of the Jianchuan county seat is mainly concentrated in the central and northern regions. Therefore, it is difficult to ensure the rationality of the location of emergency shelters. Furthermore, due to the particularity of urban land use, the rationality regarding the location of emergency shelters was not guaranteed.

The data required for this paper mainly consist of the topographic map, the current situation of land use, the current road map, the distribution data of existing emergency shelters, and the population data of neighborhood communities in the Jianchuan county seat. Among them, the resident population data is used as demand points. The process of generating demand points involves: (1) generating a regular grid for the study area using ArcGIS software; (2) obtaining the center point of each residential 
area by extracting the center point of the grid; and (3) removing the demand points which are outside the construction land and on the road, and which are adjusted accordingly with the topographic map to maintain the integrity of the living area. In this manuscript, we have a total of 443 demand points. The facility points mainly come from two aspects: on the one hand, it mainly includes existing facilities. On the other hand, it mainly uses existing urban parks, plazas, school playgrounds, open spaces and other places to select a certain scale (with an area of over $0.01 \mathrm{~km}^{2}$ ), and its entrance and exit are connected with the main road of the city as a facility. In our paper, 18 facility points (including six existing ones) were obtained by screening.

\section{Methods}

In this section, we put forward multi-level location models for different grades of emergency shelters in order to minimize the travel and construction costs and to maximize the coverage rate. Then, the actual service of emergency shelters was determined using GIS software and the Weighted Voronoi Diagram (WVD), a mathematical model that considers the limitation of site capacity. Finally, the space layout was adjusted through the combination of the actual urban land and the construction position. The corresponding models are detailed in this paper. The process of multi-level location-allocation modeling approach is illustrated in Figure 2. The whole modeling process was divided into two parts: (1) based on the primary location models and assumptions, building multi-level location models for emergency shelters to determine the location and number of emergency shelters, (2) by dividing the service scope of the emergency evacuation site and the capacity of the analysis site itself, it was judged whether the population gap of the emergency shelter is greater than $20 \%$ [4]. If yes, new emergency shelters need to be added; otherwise, the whole process ends. In addition, it is necessary to combine the status quo of urban land use and the construction conditions of alternative facilities to comprehensively judge and finally determine the location and quantity of emergency shelters.

Some basic assumptions for the models are:

(a) The locations of candidate emergency facilities and demand points are known and discrete;

(b) The distance between the candidate emergency facilities and demand points is known;

(c) If the demand point is covered by the service area of the facility, it will only be served by one facility.

(d) If a facility can cover $80 \%$ of the demand points around it and accommodate $80 \%$ of the population within its service scope, it is considered to be a reasonable facility [4].

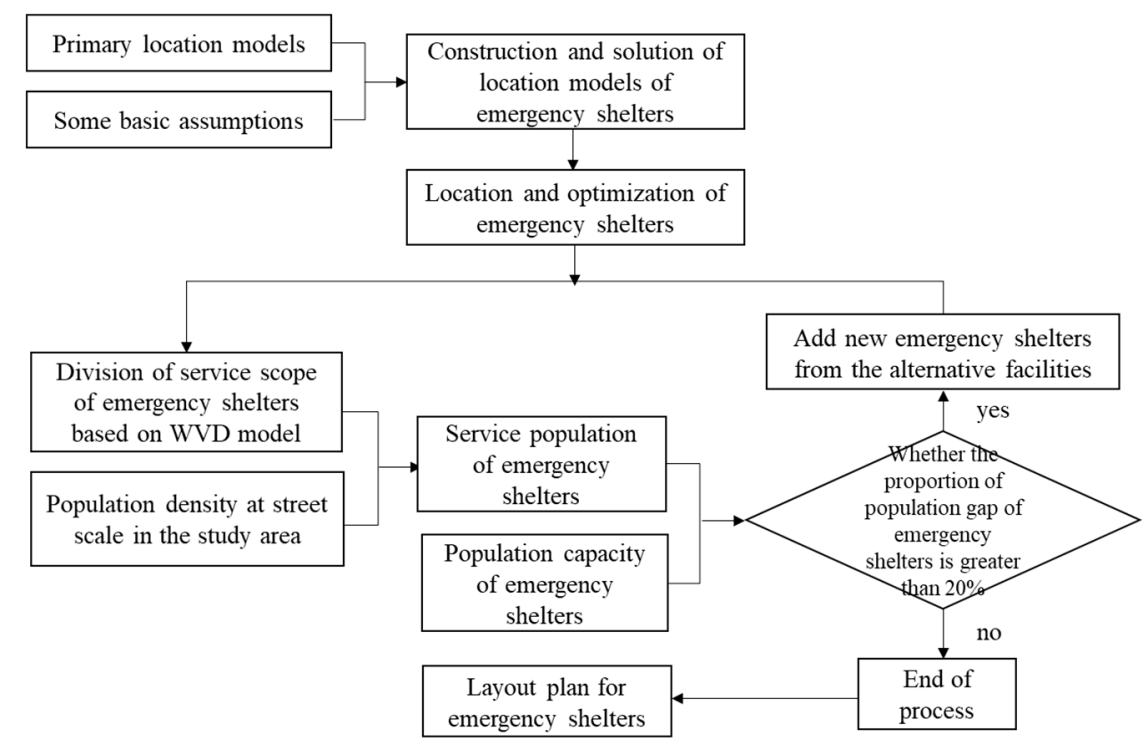

Figure 2. The process of the multi-level location-allocation modeling approach. 


\subsection{The Multi-Level Location Models for Emergency Shelters}

The location of emergency shelters often considers the efficiency and fairness of the arrival of people, as well as the safety of the site. The emergency shelter is an important place to protect personal safety when a disaster occurs. The size of its service is the best embodiment of whether its spatial layout is fair or not. Therefore, the location and number of emergency shelters should be set so that all demand points are within the effective service range of the emergency shelter. That is, each demand point in the evacuation area can use the services provided by the emergency shelter in the specified travel distance. The "multi-level" refers to different levels of emergency shelters. In this paper, we classify emergency shelters into interim emergency shelters, fixed emergency shelters, and central emergency shelters. The multi-level location models mentioned in this paper refer to the location model system for different types of emergency shelters.

From the perspective of government finance, it also requires considering the economy of the layout of emergency shelters to ensure that the largest number of residents can be served with the lowest number of facilities and the lowest building costs. Considering that the scale of small cities is lower than large and medium cities, and the land limitation of small cities, in this paper, the lower limit standard for the service radius of emergency shelters is taken into account. Based on the reference standards in China, the authors attempted to set the maximum service radius of the fixed emergency shelters to $2 \mathrm{~km}$, and the maximum service radius of central emergency shelters to $8 \mathrm{~km}$. The specific location models are described as follows.

\subsubsection{Interim Emergency Shelters}

An interim emergency shelter is one of the most basic levels in the emergency evacuation system, and it is the first place for residents to take refuge when a disaster occurs. It contains great choices for interim emergency shelters, which is typically difficult to be solved through quantitative methods of location selection problems. However, it would be feasible by utilizing a variety of areas of space. Therefore, this paper mainly focuses on the analysis of fixed emergency shelters and central emergency shelters.

\subsubsection{Location Model of Fixed Emergency Shelters}

The location selection of a fixed emergency shelter should be based on the full coverage of the requirement points in the coverage area and minimize the total cost. The construction process of this model includes the minimum number of facilities required to cover all the requirement points in the studied area by minimizing the facility point model; on the basis of the minimum number of facilities identified, the total cost of the facility configuration is minimized by impedance settings. Specific mathematical models are expressed as follows $[8,10]$.

Minimizing the facility point model (MPM)

$$
\begin{gathered}
\text { MPM }: \min z=\sum_{j \in L} x_{j} \\
\text { s.t. } \sum_{j \in V_{i}} x_{j}=1, \forall i \in D \\
D=\left\{D_{i} \mid i=1,2, \ldots, n\right\}, n \in N * \\
V_{i}=\left\{i \mid d_{i j} \leq r\right\} \\
x_{j}=\left\{\begin{array}{c}
1, \text { if the facility point } L_{j} \text { is identified for emergency point }, \forall j \in L \\
0, \text { otherwise } \\
L=\left\{L_{j} \mid j=1,2, \ldots, m\right\}
\end{array}\right.
\end{gathered}
$$


where $D$ is the set of demand points. $L$ is the set of candidate facility points. $n$ is the number of demand points. $m$ is the number of candidate facility points. $V_{i}$ is the set of candidate service facilities for demand point $i . r$ is the maximum service radius of the fixed emergency shelters and is set it to $2 \mathrm{~km}$ in this study. $d_{i j}$ is the parameter of the distance from point $i$ to point $j$.

Equation (1) is used to minimize the number of facilities. Equation (2) ensures that each demand point $i$ is covered by only one facility point. In this study, each facility point can be used as an emergency shelter. Equation (3) is an integer constraint of $x_{j}$. Equation (4) is the set of candidate service facilities for demand point $i$, and the basic condition for its satisfaction is that the parameter of the distance from point $i$ to point $j$ is less than the effective emergency distance. Equation (5) refers to the range and condition of $x_{j}$. Finally, Equation (6) is an integer constraint of $L_{j}$.

\section{Minimized impedance model (MIM)}

$$
\text { MIM }: \min z=\sum_{j \in L} C_{j} x_{j}
$$

where $C_{j}$ is the travel cost to reach each emergency point. In this paper, we use the travel time (unit: $\min$ ).

The minimized impedance model is obtained by the minimization of the facility point model. By increasing the cost of travel, the site selection of the facilities is considered efficient, while taking into account the fairness. Besides, Equation (7) demonstrates that the total travel distance of the demand points, which are covered by the emergency point, to the emergency point $j$ is minimized.

\subsubsection{Location Model of Central Emergency Shelters}

The location of a central emergency shelter should maximize the coverage of the facility points when the site is selected to meet the established travel distance criteria. Based on the principles of economics, the location of such central emergency shelters should be combined with the location of a fixed emergency shelter [11]. The maximum coverage model (MCM) is an important variant of the MPM, the basic assumptions are the same as those for the location of fixed emergency shelters. The specific mathematical models are expressed as follows.

\section{Maximum coverage model (MCM)}

$$
\begin{aligned}
& M C M: \max z=\sum_{i \in D} a_{i} y_{i} \\
& \text { s.t. } \sum_{j \in V_{i}} y_{i} \leq x_{j}, \forall i \in D \\
& D=\left\{D_{i} \mid i=1,2, \ldots, n\right\} \\
& V_{i}=\left\{i \mid d_{i j} \leq r\right\} \\
& \sum_{j \in L} x_{j}=p(1 \leq p \leq m) \\
& x_{j}, y_{i} \in\{0,1\}, \forall j \in L, \forall i \in D(j \leq i) \\
& L=\left\{L_{j} \mid j=1,2, \ldots, m\right\} \\
& y_{i}=\left\{\begin{array}{c}
1, \text { if the demand point } D_{i} \text { is covered by the facility point } \\
0, \text { otherwise }
\end{array}\right. \\
& x_{j}=\left\{\begin{array}{c}
1, \text { if the facility point } L_{j} \text { is identified for emergency point } \\
0, \text { otherwise }
\end{array}\right.
\end{aligned}
$$


where $D$ is the set of demand points, $n$ is the number of demand points, $L$ is the set of candidate facility points, and $m$ is the number of candidate facility points. $V_{i}$ is the set of candidate service facilities for demand point $i . p$ is the number of service facilities planned to be established. $r$ is the maximum service radius of the central emergency shelters, which is set to $8 \mathrm{~km}$ in this paper. $\mathrm{a}_{i}$ is the demand of demand points and, in this paper, we use the coverage population to represent it. $d_{i j}$ is the parameter of the distance from point $i$ to point $j$.

Equation (8) is to maximize the population of the covered demand points under limited resources. In this paper, the alternative facility points for the central emergency shelter are mainly based on the location results of the fixed emergency shelter. Equation (9) indicates that when demand point $i$ is assigned to cover, one of the candidate facility points within its effective emergency distance must be selected as an emergency shelter. Equation (11) is the set of candidate service facilities for demand point $i$, and the basic condition for its satisfaction is the parameter of the distance from point $i$ to point $j$ is less than the effective emergency distance. Equation (12) expresses that the number of designated facilities is equal to $p$. Moreover, Equation (13) is the integral constraint condition of $x_{j}$ and $y_{i}$. Equations (10), (14)-(16) refer to the range and condition of $x_{j}$ and $y_{i}$.

\subsection{The Weighted Voronoi Diagram (WVD) Model for Dividing the Service Scope of Emergency Shelters}

The layout of an urban emergency shelter includes both the emergency shelter's sites selection and their service scopes, on the basis of facility location and the actual service scope of emergency shelters. The scope of the service of emergency shelters in our manuscript refers to the range of demand points that can reach the facilities within the specified time. By coupling the distribution of the population in a city, the actual service population of each emergency shelter can be achieved, so as to solve the problem of prior site selection, which fails to consider the actual capacity of the problem.

\subsubsection{The Model for Service Scope of an Urban Emergency Shelter}

The service scope of urban emergency shelters is restricted and affected by nature, society, and its own foundation, representing different service scopes. Refering to the existing studies at home and abroad in relation to the characteristics of a small mountain city, in this paper, seven factors were chosen, namely, field conditions, terrain slope, type of site, traffic connectivity, the actual effective area, impact degree of a disaster, and infrastructure conditions. The score of each factor was set to 1 (extreme) to 5 (excellent). By appropriately grading these factors, we achieved the score of each influence factor on the service scope of an emergency shelter. Thus, in this study, the service scope of emergency shelters was established in addition to the impact factors to be used in evaluation system, based on Analytic Hierarchy Process (AHP), by which the weight of the seven mentioned factors can be calculated (see Table 1).

According to the nature of the problem and the overall goal to be achieved, AHP breaks down the problem into different components and combines the factors according to the interrelated influences and affiliation of the factors to form a multi-level analytical structure model. Therefore, the problem is ultimately attributed to the determination of the relative importance of the lowest level (solutions, measures, etc., for decision making) relative to the highest level (total target) or the ranking of relative merits. The calculation process of AHP is expressed as follows:

(1) Establish a hierarchical structure model. The relevant factors are decomposed into several levels from top to bottom according to different attributes. The factors of the same layer are influenced by the factors of the upper layer or the factors of the upper layer, and at the same time they are dominated by the factors of the next layer or by the factors of the lower layer. The top layer is the target layer, usually only one factor, the bottom layer is usually the scheme or object layer, and there can be one or several levels in the middle, usually the criterion or indicator layer.

(2) Construct a judgment matrix. Starting from the second layer of the hierarchical model, for the same layer of factors belonging to each factor of the upper layer, the pairwise comparison method 
is used to construct a pairwise comparison matrix until the lowest layer. In this paper, we mainly compare the impact of different indicators on the service scope of emergency shelters.

(3) Calculate the weight vector and do a consistency check. The maximum eigenvalues and corresponding eigenvectors are calculated for each paired matrix, and consistency tests, random consistency indicators, and consistency ratios are used for consistency testing. If the test passes, the feature vector (after normalization) is the weight vector. Otherwise, it needs to be reconstructed into a pairwise comparison matrix.

(4) Calculate the combined weight vector and do the combined consistency test. Calculate the combined weight vector of the lowest layer to the target and perform the combined consistency test according to the formula. If the test passes, the decision can be made according to the result expressed by the combined weight vector. Otherwise, the judgment matrix needs to be reconstructed.

By running the yaahp software, we can obtain all the parameters. The value of lambda Max is 7.7376 and the consistency ratio is $0.0904<0.1$, indicating that the obtained weight value is valid.

Table 1. Influence factors and their weight values of service scope of emergency shelters.

\begin{tabular}{|c|c|c|}
\hline Influence Factors & Explanation & Weight Values \\
\hline The field conditions & $\begin{array}{l}\text { Whether the terrain in the study area is flat, } \\
\text { whether the foundation is strong, and whether } \\
\text { there is a geological disaster-prone area }\end{array}$ & 0.0337 \\
\hline The terrain slope (Unit: degree) & Slope of location in different places & 0.0337 \\
\hline The site types & $\begin{array}{l}\text { Available area and facility availability for } \\
\text { different site types }\end{array}$ & 0.0750 \\
\hline The traffic convenience (Unit: m) & $\begin{array}{l}\text { Whether the width of the road around the site } \\
\text { can meet the needs of evacuation and rescue } \\
\text { transportation }\end{array}$ & 0.0422 \\
\hline The actual effective area (Unit: $\mathrm{m}^{2}$ ) & $\begin{array}{l}\text { The actual area of the refuge area in the site } \\
\text { after removing the water area, roads, trees, } \\
\text { houses, mountains, etc. }\end{array}$ & 0.5587 \\
\hline The possibility of disaster impact & $\begin{array}{l}\text { Mainly refers to the flammability of buildings } \\
\text { in the site and the distance from the } \\
\text { surrounding buildings }\end{array}$ & 0.1514 \\
\hline The conditions of infrastructure & $\begin{array}{l}\text { Including basic requirements for domestic } \\
\text { water, fire, temporary power supply and } \\
\text { communication in the premises }\end{array}$ & 0.1053 \\
\hline
\end{tabular}

Note: In the process of weight calculation, each indicator is divided into five levels: excellent (5 points), good (4 points), general (3 points), poor ( 2 points) and very poor (1 point).

Affected by natural, social, and transportation conditions, different emergency shelters have different service scopes. The service scope of an emergency shelter is mainly based on its coverage radius, which is the coverage of the outside of the emergency site. Based on the weight value calculations, the weighted coverage radius and the weighted distance can be obtained according to the actual position of each emergency shelter. The calculation process is expressed as follows:

$$
R_{j}=R_{1}+R_{0} \sum_{j=1}^{n} \frac{A_{j} w_{j}}{5}(j=1,2,3, \ldots, n)
$$

where $R_{i}$ is the weighted coverage distance of an emergency shelter. $R_{0}$ is the coverage radius of emergency shelters in various grades (i.e., $2 \mathrm{~km}$ for a fixed emergency shelter; $8 \mathrm{~km}$ for a central emergency shelter). $R_{1}$ is the radius of the emergency shelter itself, $A_{j}$ is the score of each influence factor, and $w_{j}$ is the weighted value of each influence factor. 


\subsubsection{The Weighted Voronoi Diagram (WVD) Model for Emergency Shelter Services}

The traditional methods of emergency shelter services mainly rely on subjective interpretation, dividing basically the facilities according to the street network and communities, excluding a scientific basis for the division of responsibilities. In this paper, in order to define the service scope of urban emergency shelter, we determine the coverage radius of the emergency shelters, which are used to calculate the weighted distance; next, the service scope of each emergency shelter was determined by WVD. As a special form of the location analysis model, WVD built a space adjacent model that does not depend on the coordinate geometry; its principle is spatial interaction theory, and it can be clearly expressed as a lateral adjacent relation in GIS, a better simulation of the adjacent choice in reality. In the service scope of emergency shelters, through the selection of impact factors and the determination of the weighted values, a weighted Voronoi diagram can be used to make space segmentation, thus the service scope of an emergency shelter can be divided [26]. The specific construction model is presented as:

$$
\begin{gathered}
\text { Voronoi }\left(P_{i}\right)=\left\{p \mid d\left(p, p_{i}\right) \leq d\left(p, p_{j}\right), j \neq i\right\}(i=1,2, \ldots, n) \\
P=\{p 1, p 2, \ldots \ldots p n\}(2 \leq n<\infty) \\
\text { Voronoi }\left(p_{i}, w_{i}\right)=\left\{p \mid \frac{d\left(p, p_{i}\right)}{w_{i}} \leq \frac{d\left(p, p_{j}\right)}{w_{j}}, j \neq i\right\}(i=1,2, \ldots n)
\end{gathered}
$$

where $P$ in Equation (19) is the set of the discrete growth points on the Euclidean plane. $d\left(p, p_{i}\right)$ and $d(p$, $p_{j}$ ) are the Euclidean distances between these two growth points, respectively. $w_{i}$ is weight value of the growth point $p_{i}$.

Equation (20) is re-written as Equation (18), defining the weighted distance of each growth point as Euclidean distance, which is divided by the weight value. In this study, the large number of polygons produced by the important growth points has a large scope of influence. The revised model can better reflect the weights of different growth points in the spatial scope, and hence appropriate for the determination of urban emergency shelters.

By running the Voronoi Map creation function in GIS, the service scope of each emergency shelter during the site selection stage can be obtained. Combining the actual land use situation with the population density, we can calculate the coverage rate of each emergency shelter and verify whether the location of the site is reasonable or not. The specific construction model is presented as:

$$
\begin{gathered}
C=100 \times P(a) / P(c) \\
P(a)=S_{1} \times 2 \\
P(c)=S_{2} \times D e
\end{gathered}
$$

where $C$ is the coverage rate of each emergency shelter. $P(a)$ is the number of people that can be accommodated by each emergency shelter. $S_{1}$ is the effective area of each emergency shelter. Equation (22) shows the calculation process of the number of people that can be accommodated by each emergency shelter. In our manuscript, we have adopted the national unified standard $\left(2 \mathrm{~m}^{2}\right.$ per person of shelter area). $P(c)$ is the number of people that is within the scope of the service of each emergency shelter. $S_{2}$ is the service scope of each emergency shelter. $D e$ is the population density of study area.

\section{Results and Discussion}

\subsection{Location-Allocation Results of Fixed Emergency Shelters}

In the case study, by running a minimized facility point model with ArcGIS software, we can obtain the minimum number of facilities needed to cover demand points in the study area. The model 
calculation takes the actual length of the county road in the Jianchuan County Seat as the travel cost, and the impedance transformation defaults to linear. The results indicate that the number of fixed emergency shelters required to achieve coverage for all demand points is 18 .

In terms of fairness, all emergency shelters should cover $100 \%$ of the demand points in the study area so that everyone at each demand point can reach the nearest emergency shelter within the specified travel time. But in reality, the spatial distribution of the population is uneven. The main urban area has a relatively dense population distribution, while the suburban area has a relatively scattered population distribution and a low population density. Therefore, the large number of emergency shelters placed in these areas tends to result in low usage rates. In terms of economy, it is very unreasonable to set up emergency shelters in these areas.

On the basis of minimizing the facility point model, running the minimum impedance model can simultaneously consider the fairness and economy of the emergency shelter, and finally determine the number of fixed emergency shelters. The model calculation takes the actual road length of the Jianchuan county seat as the travel cost, and the number and coverage of the emergency shelters in the model calculation process are shown in Table 2. Considering the efficiency principles of emergency shelters, the minimized impedance model is run on the basis of minimizing the facility point model, which minimizes the travel cost as well. The number and coverage of the fixed emergency shelter facilities in the Jianchuan county seat are shown in Table 2. To comprehensively assess the factors affecting emergency shelter configuration, both fairness and efficiency principle, ultimately eight facilities were selected (its coverage rate reached $80 \%$ ).

Table 2. The number and coverage rate of the fixed emergency shelters in the Jianchuan county seat.

\begin{tabular}{ccc}
\hline Number of Facility Points & Number of Demand Points Covered & Coverage Rate (\%) \\
\hline Less than & - & Less than 75.00 \\
6 & 333 & 75.17 \\
7 & 346 & 78.10 \\
8 & 356 & 80.36 \\
9 & 364 & 82.17 \\
10 & 371 & 83.75 \\
11 & 378 & 85.33 \\
12 & 383 & 86.46 \\
13 & 386 & 87.13 \\
14 & 399 & 90.07 \\
15 & 411 & 92.78 \\
16 & 425 & 95.94 \\
17 & 432 & 97.52 \\
18 & 443 & 100 \\
\hline
\end{tabular}

The fixed emergency shelter is the main place for long-term refuge and centralized rescue in cities. In the optimization process of site selection, the following principles are mainly considered: (1) the geographical conditions, demonstrating that the fixed emergency shelters should be located in flat terrains with better geological conditions, as well as avoiding the influence area of the earthquake fault zone; (2) traffic conditions, meaning that the layout of the fixed emergency shelters should be located in an area with convenient transportation, and guarantees at least two roads connecting the main roads with the width of at least $7 \mathrm{~m}$; (3) infrastructure conditions, showing that the fixed emergency shelters should be set in areas with better basic conditions; (4) the distribution of the existing emergency shelters, meaning that the location selection of emergency shelters should consider the distribution of the existing emergency shelters and avoid the over concentration of facilities; and (5) the population distribution, demonstrating that the distribution of fixed emergency shelters should be adjusted according to the distribution of the population.

Based on the analysis of the location selection of the fixed emergency shelters, the Jianchuan county seat is located in the relatively gentle section of the dam area and the variation in slope is small. 
There is no seismic fault zone inside, nor any large water areas. Through the analysis of the town's major hazard source buffer, there is no emergency shelter located in the radiation range of the city's major hazard source at a distance of $1 \mathrm{~km}$. In the eight exiting fixed emergency shelters, Jingfeng Park is unsuitable as a fixed emergency shelter due to the limitation of its actual effective area. Therefore, its location should be adjusted. Since Jingfeng Park, Jinhua middle school, and Jianchuan high school are nearby, and the scope of the demand points which they cover is close, thus, the authors attempted to merge Jianchuan middle school and Jinhua high school as a new fixed emergency shelter. As a result, there are seven fixed emergency shelters, and the results of the model are displayed in Figure 3, with a coverage rate of $81.72 \%$, satisfying the requirements.

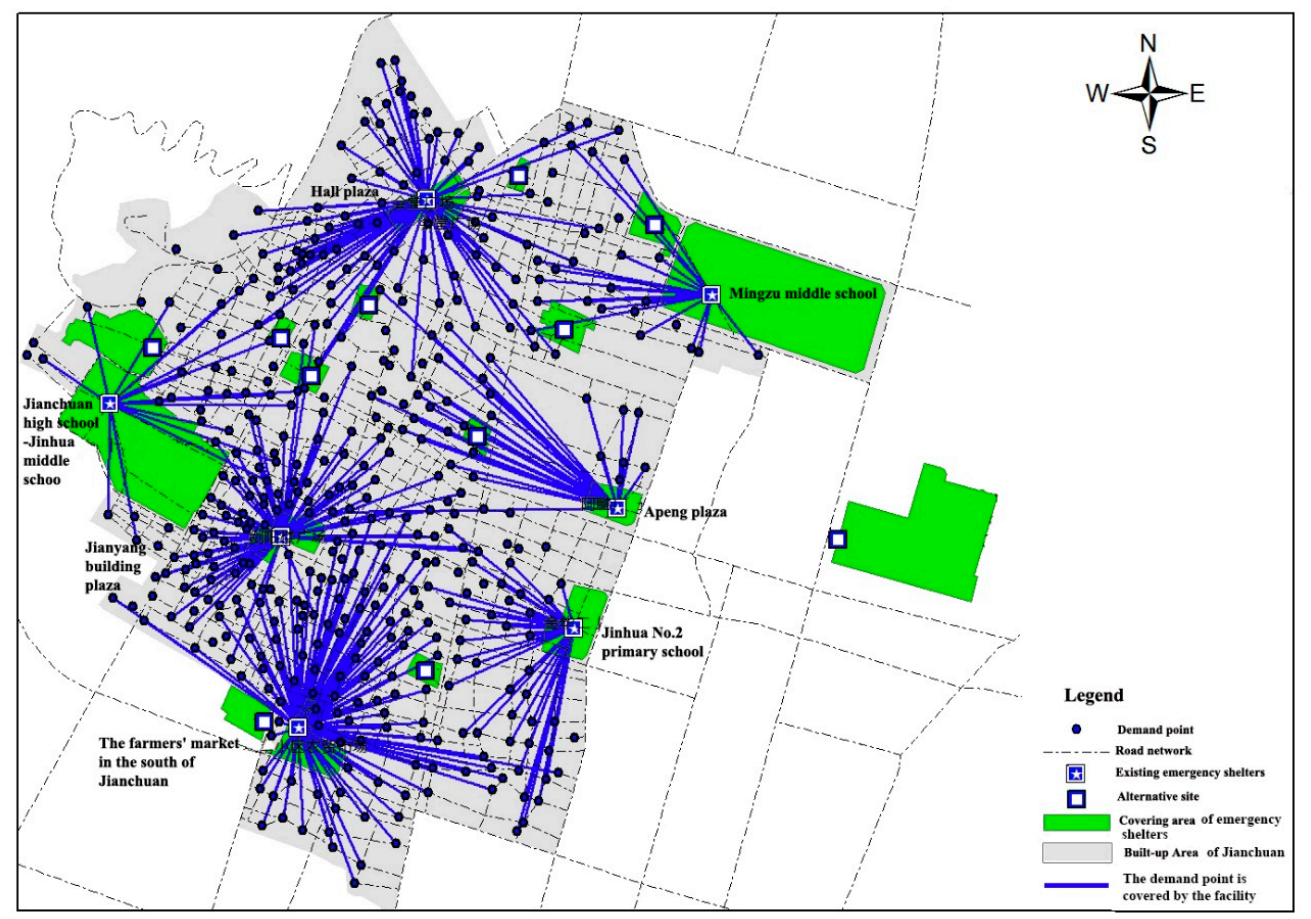

Figure 3. The results of the optimal location of the fixed emergency shelter in the Jianchuan county seat.

\subsection{Location-Allocation Results of Central Emergency Shelters}

The location of the central emergency shelter is based on the siting model of the established central emergency shelter. On the basis of the facility points of the fixed emergency shelters, the maximum number of demand points can be covered by maximizing the coverage model and corresponding constraint conditions. The number and coverage rate of central emergency shelters are listed in Table 3. In order to comprehensively take into account factors affecting emergency shelter configuration (i.e., fairness and efficiency principle), three central emergency shelters were eventually selected.

Table 3. The number and coverage rate of the central emergency shelters in the Jianchuan county seat.

\begin{tabular}{ccc}
\hline Number of Facility Point & Number of Demand Point Covered & Coverage Rate (\%) \\
\hline 1 & 331 & 74.72 \\
2 & 343 & 77.42 \\
3 & 357 & 80.59 \\
4 & 366 & 82.62 \\
5 & 372 & 83.97 \\
6 & 379 & 85.55 \\
7 & 384 & 86.68 \\
\hline
\end{tabular}


The central emergency shelter is the largest and the perfect emergency shelter in an urban emergency system. Regarding its location selection and optimization process, the main principle is similar to fixed emergency shelters. In addition, it is noteworthy that the location of a central emergency shelter should be selected based on the location of fixed emergency shelters, providing appropriate transportation links as far as possible between individual locations. Even in some individual locations, the central and fixed emergency shelters can be merged together considering economic efficiency. According to the analysis of the model of three places, we can conclude that (see in Figure 4): (1) from the perspective of urban design and master planning for the Jianchuan county seat, the location of the Jianchuan Hall Square is defined as the central emergency shelter, and the radiation of its service area is mainly towards the northern region of the whole town, thus it can be selected as one of the central emergency shelters; (2) Jianchuan high school and Jinhua middle school, as fixed emergency shelters, are mainly serving the population of the ancient town and the transportation condition is better, which is more reasonable to be considered as the center of the emergency shelter; and (3) the farmer's market has been located in the southern part of the county seat. The main service targets are the residents of the south part of the county seat. Therefore, it is reasonable to nominate it as an emergency shelter. The results of the analysis show that the optimal layout of the three center emergency shelters is appropriate.

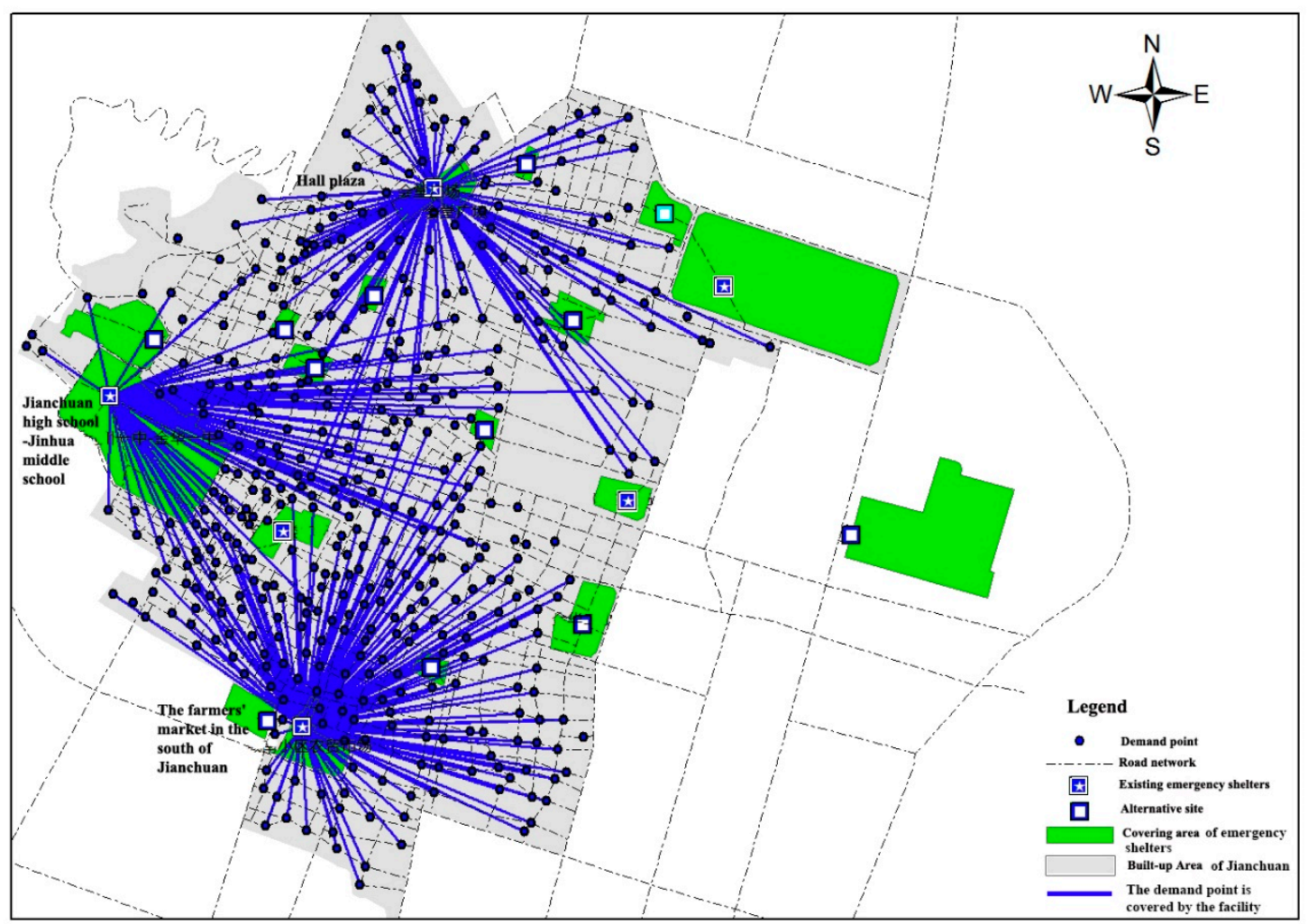

Figure 4. The results of the optimal layout of the central emergency shelter in the Jianchuan county seat.

\subsection{Results and Analysis of Service Scopes Division}

The layout of an urban emergency shelter includes both the site selection of emergency shelters and their service scopes, on the basis of facility location and the actual service scope of emergency shelters. By coupling the distribution of population in a city, the actual service population of each emergency shelter can be achieved, so as to solve the problem of prior site selection, which cannot consider the actual capacity of the problem. According to the Equations (19)-(21), and the actual position of the emergency shelters of the Jianchuan county seat, the basic parameters and the weighted distance of each emergency shelter can be calculated (see Table 4). Based on the established model and 
the results presented in Table 4, the function of Voronoi Map, based on ArcGIS output, was used to create the service scope of the emergency shelters in the Jianchuan county seat (see Figure 5).

Table 4. The basic parameters and the weighted distance of each emergency shelters at the Jianchuan seat.

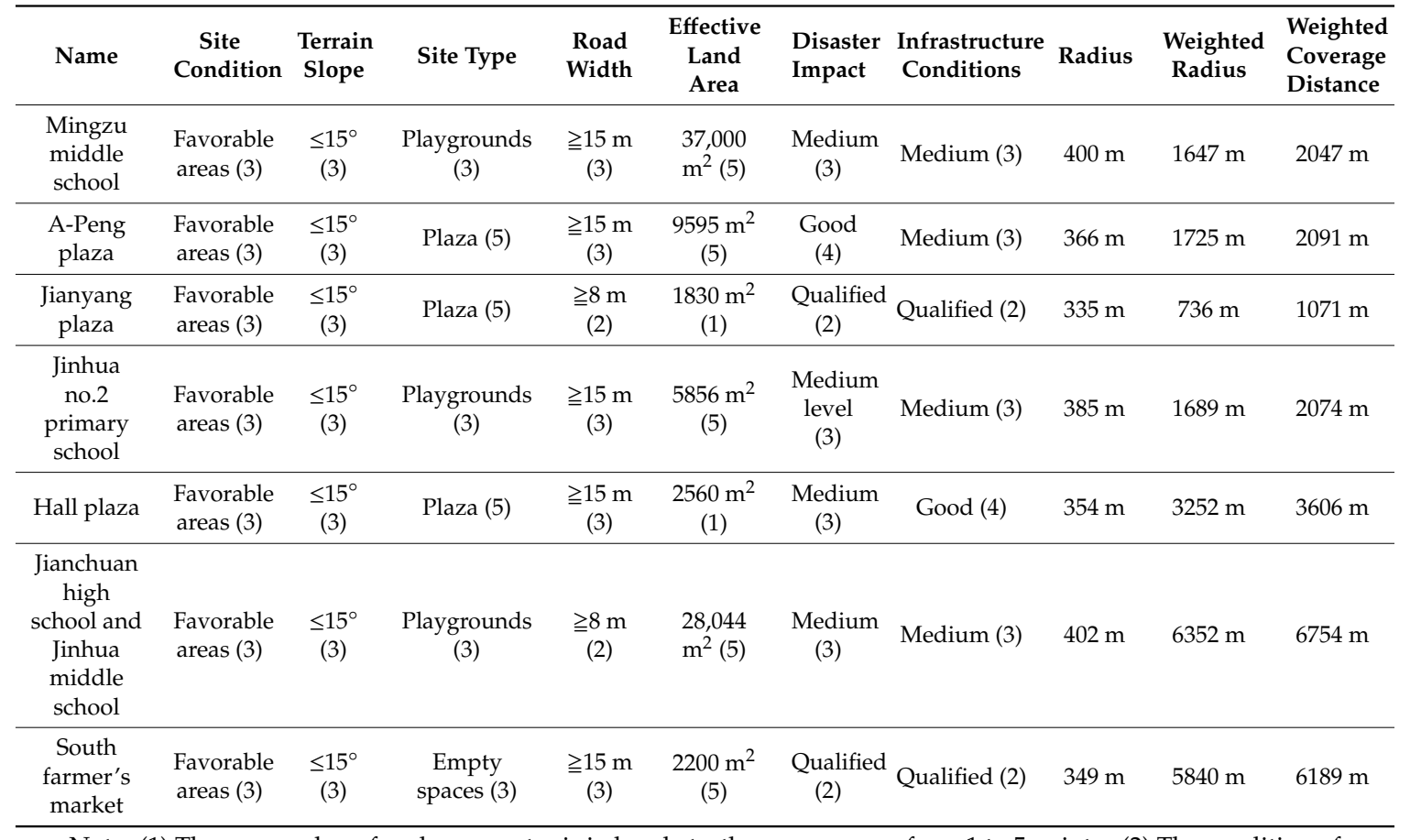

Note: (1) The score value of each parameter is in brackets, the score ranges from 1 to 5 points.; (2) The condition of site is mainly concerned with the possibility of earthquakes, landslides, debris flow and other disasters. There are three levels of advantageous location, unfavorable location, and dangerous lot; (3) The possibility of disaster impact mainly considers the flammability of the building, the distance from the surrounding buildings, whether it is in the fire prone area, and whether it is far from the danger source. There are three grades: good, medium, and qualified.

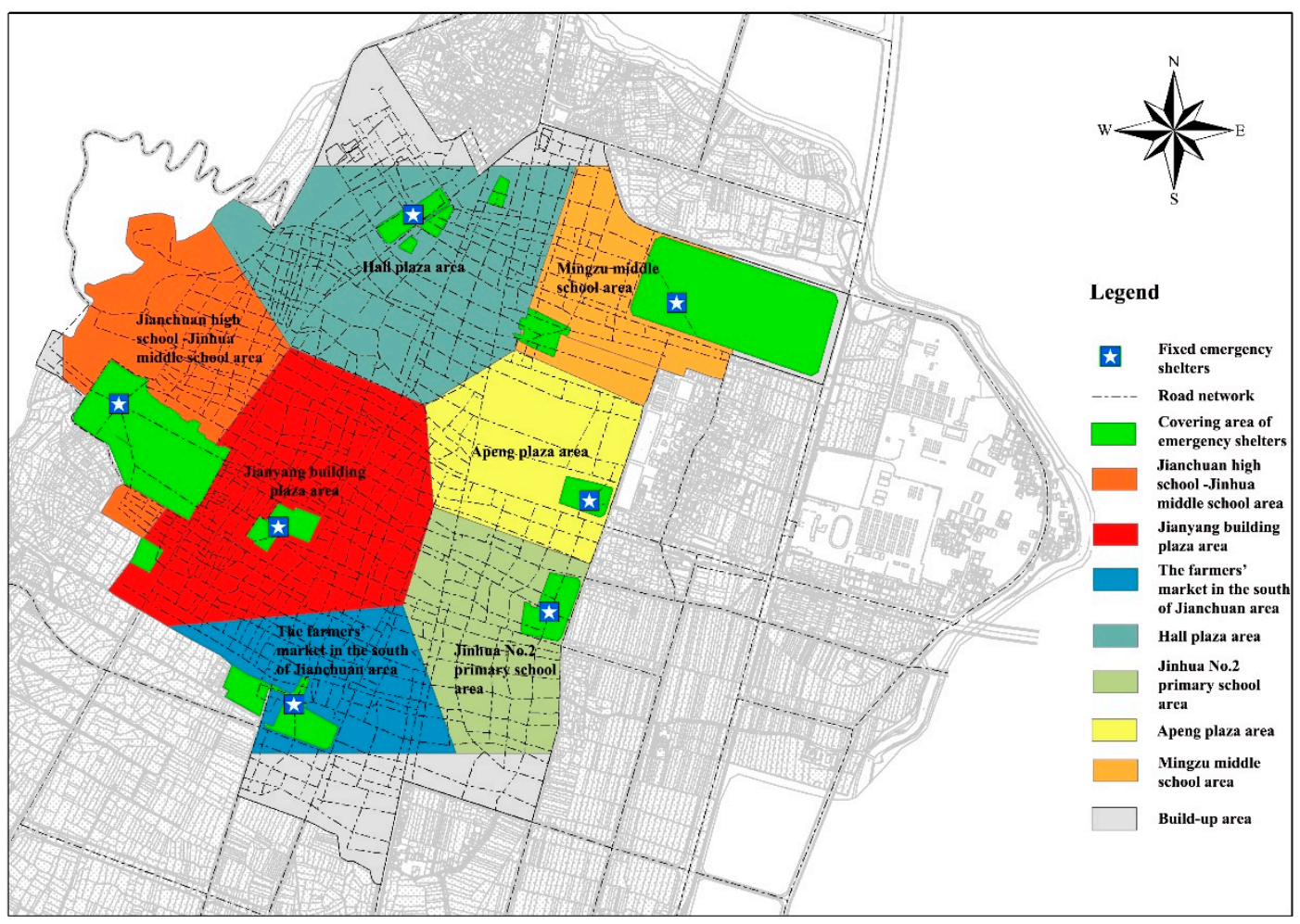

Figure 5. Service scope of emergency shelters in the Jianchuan county seat. 
The number of people involved in the service scope of the emergency shelter can be obtained by superimposing the service scope of the emergency shelter with the map of population density. Then, the coverage rate of the emergency shelters can be achieved on the basis of the number of people served and the capacity limitation. The capacity limitation of emergency shelters refers to the actual number of people in each emergency shelter. Through the effective tolerance area and the standard value of the per capita refuge area of each site, we can find that the per capita refuge area of this paper is $2 \mathrm{~m}^{2}$ each person.

According to the results mentioned in Table 5, seven fixed emergency shelters, namely, Mingzu middle school, A-Peng Plaza, Jinhua No. 2 primary school, and Jianchuan high school and Jinhua middle school, can fully meet the demand of the service within the scope of the surrounding population. Among them, the coverage rate of South farmer's market has reached $80 \%$, basically satisfying the demands of the vast majority of the surrounding population. Considering that the south of this area is mainly housing estate, it still requires expanding its space in order to increase the coverage rate. The coverage rate of Jianyang Building Plaza and the hall square is only 75.18 and $29.84 \%$, respectively, which is not up to $80 \%$. Thus, it is difficult to meet the requirements of the majority of people and it is essential to adjust and optimize these two sites.

Table 5. The number of people serving and the coverage rate of emergency shelters in the Jianchuan county seat.

\begin{tabular}{|c|c|c|c|c|}
\hline Name & $\begin{array}{l}\text { Effective } \\
\text { Land Area } \\
\quad\left(\mathrm{m}^{2}\right)\end{array}$ & $\begin{array}{l}\text { Population } \\
\text { Coverage }\end{array}$ & $\begin{array}{l}\text { The Number of } \\
\text { People Can Be } \\
\text { Accommodated }\end{array}$ & Coverage Rate $(\%)$ \\
\hline Mingzu middle school & 37,000 & 1666 & 18,500 & 1110.44 \\
\hline A-Peng plaza & 9595 & 1942 & 4796 & 246.96 \\
\hline Jianyang building plaza & 1830 & 1217 & 915 & 75.18 \\
\hline Jinhua No. 2 primary school & 5856 & 1894 & 2928 & 154.59 \\
\hline Hall plaza & 4560 & 4233 & 2280 & 53.86 \\
\hline $\begin{array}{l}\text { Jianchuan high school and Jinhua } \\
\text { middle school }\end{array}$ & 28,044 & 3994 & 14,022 & 351.08 \\
\hline South farmer's market & 2200 & 1350 & 1100 & 81.48 \\
\hline
\end{tabular}

According to Table 5, it can be seen that, firstly, the coverage rate of the Hall Plaza is $53.86 \%$, with satisfactory infrastructure, yet it is difficult to provide its service scope through the perfect facilities configuration. In addition, the area of new emergency shelter may increase to solve the service scope issue. There are three alternative sites in this area as shown in Table 6. The overall infrastructure of Land Block 1 and 2 is poor, the transformation is difficult, and it is not connected with the main road of the city, and the traffic connectivity is poor as well. Therefore, these two places are not suitable to be regarded as alternative sites.

Table 6. Basic information of each alternative site.

\begin{tabular}{ccccccc}
\hline Area & Place & Type & $\begin{array}{c}\text { Land Area } \\
\left(\mathbf{m}^{\mathbf{2}}\right)\end{array}$ & $\begin{array}{c}\text { Infrastructure } \\
\text { Conditions }\end{array}$ & $\begin{array}{c}\text { Traffic } \\
\text { Conditions }\end{array}$ & $\begin{array}{c}\text { The Ease of } \\
\text { Transformation }\end{array}$ \\
\hline \multirow{3}{*}{ Hall Plaza Area } & Land Block 1 & Parking lot & 2750 & Good & Good & Easy \\
& Land Block 2 & Vacant lot & 10095 & Poor & General & Difficult \\
Lianyang Plaza & Land Block 3 & Vacant lot & 1310 & General & Good & Difficult \\
Area & Land Block 4 & Vacant lot & 4303 & Poor & Convenient & Difficult \\
\hline
\end{tabular}


As an emergency rescue, Land Block 3 has a perfect infrastructure. Its internal parking lot is mainly used for parking fire fighting vehicles. Through transformation, Land Block 3 can be used as emergency shelters since its transportation is accordingly convenient, thus, it can be used as a new emergency shelter to alleviate the bearing pressure of the Hall Plaza. Secondly, the coverage rate of Jianyang Building Plaza is only $75.18 \%$, which is relatively low, while the gap in service population is considerable. Therefore, upgrading the facilities' configuration can hardly meet the needs of a service area. Furthermore, Jianyang Building Plaza, located in the ancient district of Jianchuan county seat, is constrained by the road width, land scale, and the need of ancient city protection. A feasible method is to build a new emergency shelter in the studied region. There is only one alternative site in this area (see Table 6). Although the basic condition of Land Block 4 is poor, traffic connectivity is better, based on square renovation, it can be built into an emergency shelter for alleviating the needs of the people in the southwest part of that ancient town.

Finally, the distribution and service scope of the emergency shelters in the Jianchuan county seat (see Figure 6) and the population coverage rate of emergency shelters are shown in Table 7. Through the data analysis in Table 7, it can be seen that the proposed new layout plan is reasonable and effective.

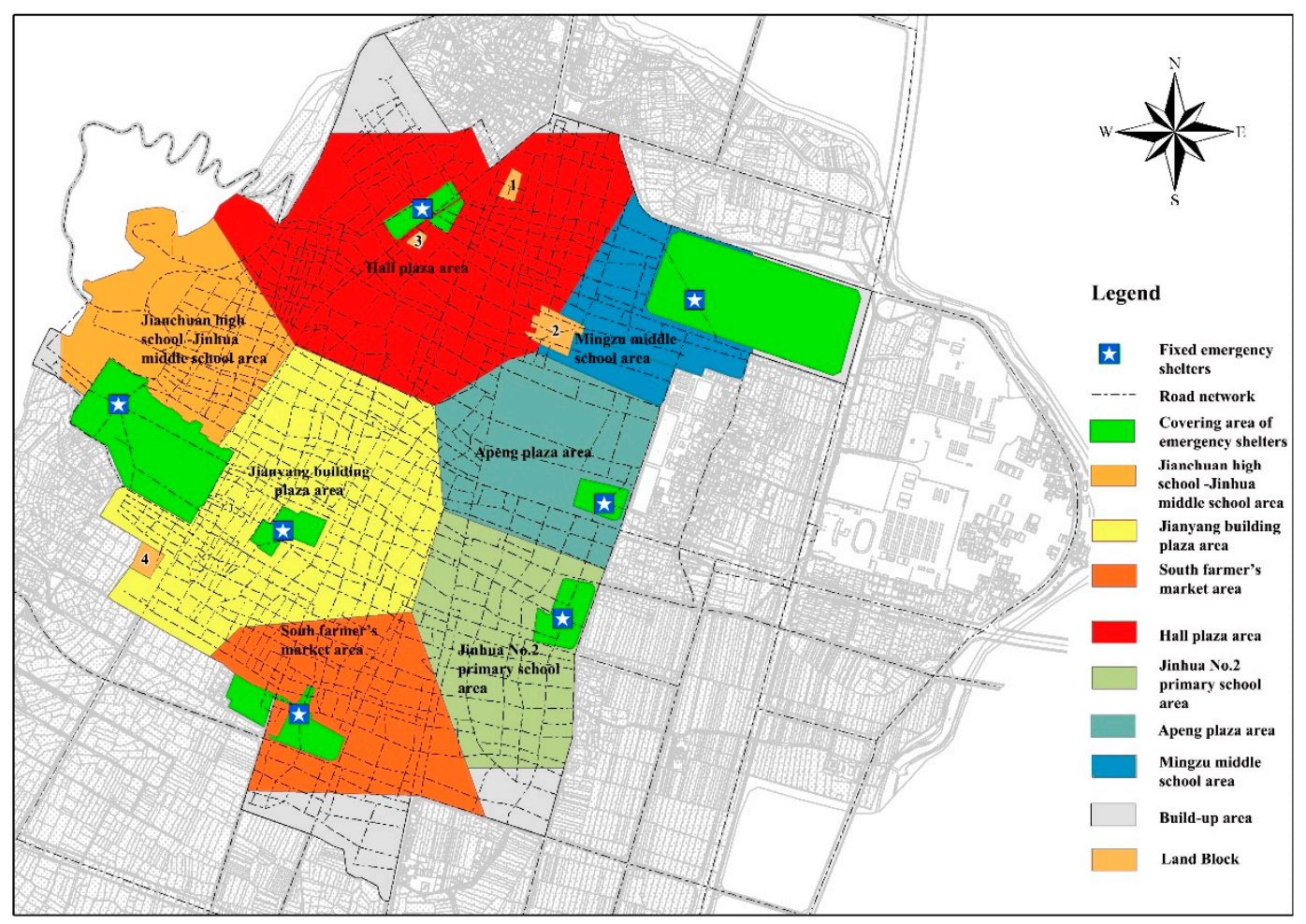

Figure 6. Regional distribution and service scope of emergency shelters in the Jianchuan county seat. 
Table 7. The number of people serving and coverage rate of emergency shelters in the Jianchuan county seat after optimization.

\begin{tabular}{|c|c|c|c|c|c|}
\hline Area & Level & $\begin{array}{c}\text { Actual } \\
\text { Effective } \\
\text { Area }\left(\mathbf{m}^{2}\right)\end{array}$ & $\begin{array}{l}\text { Population } \\
\text { Coverage }\end{array}$ & $\begin{array}{l}\text { People Can Be } \\
\text { Accommodated }\end{array}$ & $\begin{array}{l}\text { Coverage } \\
\text { Rate (\%) }\end{array}$ \\
\hline $\begin{array}{l}\text { Mingzu middle } \\
\text { school area }\end{array}$ & Fixed emergency shelter & 37,000 & 687 & 18,500 & 2692 \\
\hline A-Peng plaza area & Fixed emergency shelter & 9595 & 1942 & 4796 & 246.96 \\
\hline \multirow{2}{*}{$\begin{array}{l}\text { Jianyang building } \\
\text { plaza area }\end{array}$} & Fixed emergency shelter & \multirow{2}{*}{6030} & \multirow{2}{*}{2868} & \multirow{2}{*}{3015} & \multirow{2}{*}{105.13} \\
\hline & Fixed emergency shelter & & & & \\
\hline $\begin{array}{c}\text { Jinhua No.2 primary } \\
\text { school area }\end{array}$ & Fixed emergency shelter & 5856 & 1894 & 2928 & 154.59 \\
\hline \multirow[t]{2}{*}{ Hall plaza area } & Central emergency shelter & \multirow[t]{2}{*}{7947} & \multirow[t]{2}{*}{4868} & \multirow[t]{2}{*}{3974} & \multirow[t]{2}{*}{81.64} \\
\hline & Fixed emergency shelter & & & & \\
\hline $\begin{array}{l}\text { Jianchuan high } \\
\text { school and Jinhua } \\
\text { middle school area }\end{array}$ & Central emergency shelter & 28,044 & 3994 & 14,022 & 351.08 \\
\hline $\begin{array}{l}\text { South farmer's } \\
\text { market area }\end{array}$ & Central emergency shelter & 3800 & 1350 & 1900 & 140.74 \\
\hline
\end{tabular}

\section{Conclusions}

The emergency shelter is an important place to deal with emergency incidents. Moreover, it is a safe place for citizens. Facing the interacted pressures of both urban land restrictions and insufficient local finance, layout planning for an emergency shelter system is more prominent. Traditional location models cannot simultaneously meet all the problems encountered in the process of emergency facility location. Thus, in this paper, in view of multi-level of the different types of emergency shelters, different models are taken into account through building multi-level location models of emergency shelters, aiming to minimize the travel and construction costs and maximize the coverage range. For the fixed emergency shelters, we used the MPM model and the MIM model to fulfil the requirements of full coverage of the demand points in the coverage area and minimize the total cost. For the central emergency shelters, we used the MCM model to fulfil the requirements of maximizing the coverage of the facility points when the site is selected to meet the established travel distance criteria.

Regarding the capacity limitations of the location model, in this paper, we put forward a better approach for optimal layout to divide the reasonable service scope of emergency facilities and to adjust and determine the number of facilities. In order to define the scope of urban emergency shelter services, we determined the actual service of emergency shelters based on GIS software and WVD models under the limitation of site capacity and population density, and then adjusted the space layout by combining with the actual urban land and construction position. This method can be utilized to deal with the problem of the actual capacity insufficiency and an imbalanced distribution of service scope in the process of site selection of emergency shelters.

The proposed research methods and models are applied in the Jianchuan county seat, a traditional small mountain city in China, and provide theoretical guidance and model reference for location selection at emergency shelters in other small mountain cities. In practice, however, the layout of emergency shelters is also affected by several other factors. It is difficult to simulate the scope of actual service only by selecting seven factors. In addition, the distribution of population density is also affected by many factors, e.g., commuting in day-and-night and equity cost of urban resource [27], and it is difficult to simulate the actual population distribution by dividing the population density based on the street scale as well. Moreover, based on the research performed on the layout of emergency shelters, some scenarios assume that people will be sheltered the first time after the occurrence of 
disasters to avoid disaster, but in the actual cases, the demand is changed over time, necessitating further studies in the future.

In the paper, we mainly discuss the location and optimization methods of emergency shelters. Planning emergency shelters is an effective approach to reducing the damage caused by disasters and ensuring the safety of residents. It is an important stage of disaster management [6], and the scientific nature rationality of emergency shelter's location directly affects the success or failure of rescue work. Admittedly, besides evacuation, mitigation against natural disasters by retrofitting and purchasing insurance policies is also an important strategy [28-30], and the coordination of different stakeholders in disaster management investments is critical for the social welfare [31]. In these aspects, we will conduct an in-depth analysis in future research, and propose corresponding countermeasures for the better implementation and construction of emergency shelter planning.

Author Contributions: Y.S. designed the research framework and method, analyzed the data, results, and wrote the first draft. G.Z. contributed to the data analysis, results and discussion and provided feedback on the final draft of the manuscript. L.X., Q.Z., and J.D. participated in the review of the manuscript and contributed to the language proofreading. J.D. provided services for the language editing of the revised manuscript.

Funding: This research was funded by the Humanities and Social Science Project of Ministry of education of China (grant number: 18YJAZH151) and the Research and Development Fund and Talent Startup Project of Zhejiang A\&F University (grant number: W20190029).

Acknowledgments: In this section you can acknowledge any support given which is not covered by the author contribution or funding sections. This may include administrative and technical support, or donations in kind (e.g., materials used for experiments).

Conflicts of Interest: The authors declare no conflict of interest.

\section{References}

1. Shi, Y.; Zhai, G.; Zhou, S.; Lu, Y.; Chen, W.; Liu, H. How can cities adapt to a multi-disaster environment? Empirical research in Guangzhou (China). Int. J. Environ. Res. Public Health 2018, 15, 2453. [CrossRef] [PubMed]

2. Shi, Y.; Zhai, G.; Zhou, S.; Lu, Y.; Chen, W.; Deng, J. How can cities respond to flood disaster risks under multi-scenario simulation? A case study of Xiamen, China. Int. J. Environ. Res. Public Health 2019, 16, 618. [CrossRef] [PubMed]

3. Zhao, L.; Li, H.; Sun, Y.; Huang, R.; Hu, Q.; Wang, J.; Gao, F. Planning emergency shelters for urban disaster resilience: An integrated location-allocation modeling approach. Sustainability 2017, 9, 2098. [CrossRef]

4. Liu, S. Location Selection and Spatial Layout of Urban Emergency Shelters-Taking Nanjing City as an Example; Nanjing Normal University Press: Nanjing, China, 2012.

5. Pérez-Galarce, F.; Canales, L.J.; Vergara, C.; Candia-Véjar, A. An optimization model for the location of disaster refuges. Socio-Econ. Plan. Sci. 2017, 59, 56-66. [CrossRef]

6. Galindo, G.; Batta, R. Review of recent developments in or/ms research in disaster operations management. Eur. J. Oper. Res. 2013, 230, 201-211. [CrossRef]

7. Chen, W.; Zhai, G.; Ren, C.; Shi, Y.; Zhang, J. Urban Resources Selection and Allocation for Emergency Shelters: In a Multi-Hazard Environment. Int. J. Environ. Res. Public Health 2018, 15, 1261. [CrossRef] [PubMed]

8. Hakimi, S.L. Optimum locations of switching centers and the absolute centers and medians of a graph. Oper. Res. 1964, 12, 450-459. [CrossRef]

9. Roth, R. Computer solutions to minimum cover problems. Oper. Res. 1969, 17, 455-465. [CrossRef]

10. Toregas, C.; Swain, R.; Revelle, C.; Bergman, L. The location of emergency service facilities. Oper. Res. 1971, 19, 1363-1373. [CrossRef]

11. Church, R.; Revelle, C. The maximal covering location problem. Pap. Reg. Sci. Assoc. 1974, 32, 101-118. [CrossRef]

12. Sweeney, D.J.; Tatham, R.L. An improved long-run model for multiple warehouse location. Manag. Sci. 1976, 22, 748-758. [CrossRef]

13. Alcada-Almeida, L.; Tralhao, L.; Santos, L.; Coutinho-Rodrigues, J. A multiobjective approach to locate emergency shelters and identify evacuation routes in urban areas. Geogr. Anal. 2009, 41, 9-29. [CrossRef] 
14. Huang, R.; Kim, S.; Menezes, M. Facility location for large-scale emergencies. Ann. Oper. Res. 2010, 181, 271-286. [CrossRef]

15. Murali, P.; Ordóñez, F.; Dessouky, M.M. Facility location under demand uncertainty: response to a large-scale bio-terror attack. Socio-Econ. Plan. Sci. 2012, 46, 78-87. [CrossRef]

16. Huang, B.; Liu, N.; Chandramouli, M. A GIS supported ant algorithm for the linear feature covering problem with distance constraints. Decis. Support Syst. 2006, 42, 1063-1075. [CrossRef]

17. Ng, M.W.; Park, J.; Waller, S.T. A hybrid bilevel model for the optimal shelter assignment in emergency evacuations. Comput.-Aided Civ. Infrastruct. Eng. 2010, 25, 547-556. [CrossRef]

18. Chang, H.S.; Liao, C.H. Planning emergency shelter locations based on evacuation behavior. Nat. Hazards 2015, 76, 1-21. [CrossRef]

19. Drezner, Z.; Wesolowsky, G.O. A new method for the multifacility minimax location problem. J. Oper. Res. Soc. 1978, 29, 1095-1101. [CrossRef]

20. Meng, P.; Hao, J. A case study on the application of location models for small town development of Daxing district Beijing. J. China Agric. Univ. 2004, 3, 88-92. [CrossRef]

21. Xue, J. Optimization Allocation Model of Primary Schools Based on Weighted Voronoi Diagram; Hebei Normal University Press: Shijiazhuang, China, 2013.

22. Kılc1, F.; Kara, B.Y.; Bozkaya, B. Locating temporary shelter areas after an earthquake: A case for Turkey. Eur. J. Oper. Res. 2015, 243, 323-332. [CrossRef]

23. Zhou, Y.; Shi, T. Location of Shenyang Park based on GIS and multi-target location model. Chin. J. Appl. Ecol. 2011, 12, 3307-3314. [CrossRef]

24. Li, G.; Ma, D.; Su, J. The division of responsibility area of urban earthquake emergency shelters based on the weighted Voronoi diagram. Archit. Sci. 2006, 3, 55-59. [CrossRef]

25. Liu, W.; Sun, W.; Xing, Y. GIS network analysis based old city educational facilities service area zoning and scale calculation: Tianjin binhai new district old city primary school example. Planners 2012, 28, 82-85. [CrossRef]

26. Yang, X.; Li, J. Research status and development trend of Voronoi diagram. China West. Technol. 2009, 8, 6-8. [CrossRef]

27. Shan, X.; Zhuang, J. Cost of equity in homeland security resource allocation in the face of a strategic attacker. Risk Anal. 2013, 33, 1083-1099. [CrossRef] [PubMed]

28. Kesete, Y.; Peng, J.; Gao, Y.; Shan, X.; Davidson, R.A.; Nozick, L.K.; Kruse, J. Modeling Insurer-Homeowner Interactions in Managing Natural Disaster Risk. Risk Anal. 2014, 34, 1040-1055. [CrossRef] [PubMed]

29. Peng, J.; Shan, X.G.; Gao, Y.; Kesete, Y.; Davidson, R.A.; Nozick, L.K.; Kruse, J. Modeling the integrated roles of insurance and retrofit in managing natural disaster risk: A multi-stakeholder perspective. Nat. Hazards 2014, 74, 1043-1068. [CrossRef]

30. Shan, X.; Peng, J.; Kesete, Y.; Gao, Y.; Kruse, J.; Davidson, R.A.; Nozick, L.K. Market Insurance and Self-Insurance through Retrofit: Analysis of Hurricane Risk in North Carolina. ASCE-ASME J. Risk Uncertain. Eng. Syst. Part A Civ. Eng. 2016, 3, 04016012. [CrossRef]

31. Shan, X.; Felder, F.A.; Coit, D.W. Game-theoretic models for electric distribution resiliency/reliability from a multiple stakeholder perspective. IISE Trans. 2017, 49, 159-177. [CrossRef]

(C) 2019 by the authors. Licensee MDPI, Basel, Switzerland. This article is an open access article distributed under the terms and conditions of the Creative Commons Attribution (CC BY) license (http://creativecommons.org/licenses/by/4.0/). 